\title{
CLOSED REDUCTION AND CAST VERSUS PERCUTANEOUS PINNING IN DISTAL RADIUS FRACTURE
}

Dr B Shrestha ${ }^{1}$, Dr A Pandey ${ }^{2}$, Dr G P Singh ${ }^{3}$, Dr K M Shrestha ${ }^{1}$, Dr R Shrestha ${ }^{4}$

ABSTRACT

\section{BACKGROUND:}

There is much debate regarding the optimal treatment of displaced distal radius fracture. The purpose of this prospective study was to compare functional and radiological outcomes of displaced distal radial fracture treated with cast or percutaneous pin.

\section{MATERIALS \& METHODS:}

Sixty patients of all age groups with non comminuted extra-articular and partially articular fracture of the distal radius were included in this study. After randomization, thirty patients were treated with cast and thirty patients with percutaneous pins. For pin group below elbow volar slab was applied for three weeks. After three weeks, slab was removed and wrist physiotherapy started. Depending on radiological and clinical union, cast or pin was removed at around six to eight weeks. Follow-up was conducted at 1 week, 3 weeks, 6 weeks, 9 weeks, 3 months and 6 months. Radiographic assessment was done at each visit, while functional scores were obtained at 6 weeks, 9 weeks, 3 months and 6 months. Outcomes at fixed time points were compared between two groups with standard statistical methods.

\section{RESULTS:}

Mean age group in pin and cast group was 27 and 42 years respectively. Other than age, both the groups were identical with respect to sex, side and dominance of hand. Overall Pin group had better functional and radiological outcome than cast group. Pin group also had better Satio grading ( $\mathrm{p} 0.002$ ) where $96.6 \%$ of cases had excellent to good result unlike cast group where only $76.7 \%$ of cases achieved these result. Complication rate also were higher in cast group especially radial collapse $(\mathrm{p}<0.001)$ and malunion $(\mathrm{p} 0.004)$.

\section{CONCLUSIONS:}

Percutaneous pinning with immobilization in volar slab in neutral position for 3 weeks has better radiological and functional outcome than cast in the treatment of non comminuted extra-articular and partially articular distal radius fracture. Moreover percutaneous pinning is a simple and safe procedure.

KEY WORDS: Cast, Closed reduction, Distal radius, Percutaneous pinning

1. Lecturer, Department of Orthopaedics and Trauma Surgery, Universal College of Medical Sciences

2. Associate Professor, Department of Orthopaedics and Trauma Surgery, Universal College of Medical Sciences

3. Professor, Department of Orthopaedics and Trauma Surgery, Universal College of Medical Sciences

4. Lecturer, Department of Community Medicine, Universal College of Medical Sciences

\author{
For Correspondence \\ Dr. Bipan Shrestha \\ Lecturer \\ Department of Orthopaedics and Trauma Surgery, \\ Universal College of Medical Sciences, Nepal \\ E-mail: bipansht@hotmail.com
}




\section{INTRODUCTION}

Fractures of the distal radius represent one-sixth of all fractures treated in emergency department ${ }^{1}$. The injury commonly affects postmenopausal osteoporotic women ${ }^{2}$. Initially, it was thought to be a simple fracture, but now, it is recognized as a complex injury because of its different fracture patterns and various treatment methods ${ }^{3}$.

The optimal treatment of distal radius fractures has changed dramatically over the last two decades for search of better treatment methods. Although cast immobilization was almost the only universal treatment in past, today it is progressing to operative interventions. Although most injured people are elderly, recent researches revealed that there is an increasing incidence rate of this fracture in all age range. ${ }^{4,5}$ Osteoporosis is the prime risk factor for fracture in elderly patients whereas motor vehicle accident is the leading cause in young adult and adult population. ${ }^{6,7}$ Therefore, the differences in age group and quality of bone may account for some of the discrepancies in treatments methods.

It has been observed that closed reduction and cast immobilization often leads to collapse of the distal radius ${ }^{8,9}$ resulting in unsatisfactory anatomical and functional results with varying degrees of deformity and disability. ${ }^{10,11}$ It has also been observed that restoration and maintenance of anatomy correlates well with the function. Cast immobilization may not be adequate in all the cases because it cannot control the movements of supination and pronation and the distal fragment gets displaced dorsally. Moreover dorsal comminution, which is a common finding, leads to dorsal tilt of the radial fragment. Therefore reducing a distal radius fracture is not the problem but maintenance of the reduction is certainly a concerned problem, especially when prolonged immobilization is required, often reduction is lost in early treatment. In many patients, incomplete restoration of radial length or secondary loss of reduction results in the complications of distal radius fracture that are frequently seen in cast treatment ${ }^{12}$.

Although closed reduction and casting is the main treatment in children as well as elderly patients, ${ }^{13}$ there are several different interventions for treating young adults and adults. Because of high functional demand, these days most of young adult and adult patients are treated operatively rather than conservative methods. The most common percutaneous K-wire fixation method provides additional stability and is one of the simplest forms of internal fixation ${ }^{14}$. Most of comminuted and displaced intra-articular fractures are better treated with plates and screw or external fixator with or without percutaneous pinning rather than pinning alone. But, many non comminuted unstable extra-articular and partially articular fractures can be treated adequately with percutaneous pinning technique. But, every treatment methods has its own merit and demerit ${ }^{15}$. Therefore, to achieve the goal of near anatomical reduction and stable fixation with least operative intervention, an easily executed technique, which carries a low morbidity, is the demand of this era. Thus, Percutaneous pin fixation is simply a role model treatment method for these fracture as it is relatively simple to perform and it produces results that are superior to closed reduction alone ${ }^{16}$. Widespread availability of necessary equipment with low cost and the comparatively more secure stabilization of unstable fracture when compared to cast support, make the method more popular ${ }^{17}$. Despite of all these advantages of percutaneous pinning, even these days many orthopedic surgeons still prefer closed reduction and cast for distal radius fracture. Therefore we wanted to know whether percutaneous pinning is really a better method than casting method in treating non comminuted extra articular and partially articular distal radius fracture so that we can provide better treatment method to the patients having this injury in our country. Thus, this study was conducted to compare the functional and radiological outcome of non comminuted extra-articular and partially articular distal radius fracture treated with closed reduction and cast or percutaneous pinning.

\section{MATERIALS \& METHODS}

This study is a prospective randomized control study of 60 patients of all age groups diagnosed with distal radius fracture. This study was performed in Universal College of Medical Sciences Teaching Hospital (UCMS-TH), Bhairahawa, Nepal from August 2011 to April 2013. All patients with noncomminuted, extra-articular and partially articular distal radius fracture were enrolled in our study. Those patients were excluded who had complete intra-articular fractures, grossly comminution, presenting later than 2 weeks, associated ulnar shaft fracture, polytrauma patients, open fractures, previous wrist or forearm fractures, congenital or other forearm anomalies, previous wrist operation, patients with dementia and psychiatric illness and patients with lost follow ups. After approval from the Institutional Review Board (IRB) of UCMS-TH, we obtained the informed consent from all patients enrolled into this study. The patients were then randomly allocated by using sealed-envelop technique to 
either the Cast group (Group A) who had undergone closed reduction and casting by standard plaster of Paris or Pin group (Group B) who had undergone closed reduction and percutaneous pinning. To standardize the method, treatment of each group was performed by the experienced Orthopaedic surgeon of UCMS-TH.

\section{PROCEDURE}

For the Cast group (Group A), closed reduction was performed under a hematoma block. After the block, fracture was reduced, below elbow cast applied and molded appropriately. Post reduction anterior posterior (AP) and true lateral radiographic view of the injured wrist was taken to confirm acceptable reduction. For the pin group (Group B), surgery was done under Supraclavicular brachial block or Intravenous anaesthesia using Ketamine and Propofol. Preoperative single dose of intravenous antibiotic was given 15 minutes before surgery. After closed reduction, two or three K-wires were inserted percutaneously under fluoroscopic guidance. First k wire of 1.5 to $1.8 \mathrm{~mm}$ was inserted via the dorsal radial side of the radial styloid process and the second K-wire was inserted from the dorso-ulnar side of the distal radius crossing the fracture and engaging far cortex making a cross configuration. Then the fracture stability was checked under continuous fluoroscopic control by dorsiflexing and palmer flexing the wrist joint. If stability was in question, third $\mathrm{K}$ wire was inserted through the radial styloid process just proximal or distal to the first $\mathrm{K}$ wire similar to first $\mathrm{k}$ wire in divergent fashion. By using this so called Tripod technique, we can have three points fixation on each side of the fracture. While inserting the pin, precaution was taken to minimize skin traction against the pins by prior retracting the skin. The Kwires were left protruding out of skin and were removed once the fracture united. Radiographs included PA view and true lateral view of the injured wrist for confirming the adequacy of the reduction alignment (radial shortening less than $5 \mathrm{~mm}$, radial inclination more than 15 degree, volar tilt between $0-15$ degree, and joint step off less than $2 \mathrm{~mm})^{18}$. Then the wrist was immobilized by applying short arm volar slab in neutral position of wrist so that immediate mobilization of elbow and fingers can be allowed.

\section{OUTCOME ASSESSMENT}

All patients were discharged after the assessment of the post reduction radiographs. They were assessed in Orthopaedics outpatient clinic at 1 week, 3 week, 6 week, 9 week, 3 month and six months. During the entire visit, radiograph was taken and documented along with pin tract dressing for pin group. For pin group, at three weeks, gentle ROM exercises of wrist were encouraged along with twice daily intermittent home exercises without slab. The slab and K-wires were removed at six weeks or eight weeks time after confirming the fracture union clinically and radiologically. The functional outcome was assessed by orthopaedic specialist physiotherapist, who was considered blinded to the procedure. The range of motion of the wrist included wrist dorsiflexion (WDF), wrist palmarflexion (WPF), supination, pronation, wrist ulnar deviation (WUD) and wrist radial deviation (WRD). It was measured using a goniometer. Grip strength was assessed by the patient's ability to hold and squeeze a rubber ball as compared to the normal hand. The mean of three readings was expressed as a percentage of the normal contralateral side. The pain level and activity of daily living (ADL) were assessed by using the grading suggested in Satio chart ${ }^{19}$. The subjective satisfaction score was also assessed by using the following grading: grade 1 for very satisfied; grade 2 for moderatelysatisfied, grade 3 for not satisfied but working, grade 4 for not satisfied and unable to work. For the radiological assessment, standardized PA and true lateral views of the wrist were taken. The radial inclination angle (RA), radial length (RL), palmer tilt/ dorsal angulation (PT/DA) and ulnar variance (UV) were measured and the measurements were compared to the normal parameter of wrist. The dorsal angulation angle of the distal radius was measured as the degrees from the neutral position. The assessment of the radiological outcomes was blinded to the method of the treatment and to the functional outcomes after removal of the slab and $\mathrm{K}$ wires. All the data was collected by structured interviews using the preformed proforma. After completion of the data collection, data was edited, coded, entered and analyzed by SPSS version 16.0. p value less than 0.05 were considered as significant.

\section{RESULTS}

\section{Demographic profile}

The mean age group of pin and cast group was 27.63 and 42.83 years respectively ( $p$ 0.002). Thirty two patients were male and 28 patients were female ( $\mathrm{p} 0.121$ ). Fall on ground was the common mode of injury in both the groups followed by road traffic accidents. Twenty eight patients $(46.7 \%)$ had fracture of left wrist and 32 patients $(53.3 \%)$ had fracture of right wrist. We observed statistically no significant difference in side and dominance of hand in both groups. 


\section{Radiological and Functional Outcome}

Table 1.Independent t test for Radiological and Functional outcome (cast vs. pin)

\begin{tabular}{|c|c|c|c|c|c|c|}
\hline & \multicolumn{2}{|c|}{ Cast } & \multicolumn{2}{|c|}{$\begin{array}{l}\text { Pin } \\
\end{array}$} & \multirow{2}{*}{ p-value } \\
\hline & & Mean & SD & Mean & SD & \\
\hline \multirow{4}{*}{ 1st week } & $\mathbf{R L}$ & 9.47 & 0.86 & 9.93 & 0.58 & 0.017 \\
\hline & RA & 19.90 & 1.71 & 20.67 & 1.73 & 0.089 \\
\hline & PT/DA & -1.77 & 4.54 & -3.83 & 4.19 & 0.072 \\
\hline & UV & 0.23 & 0.63 & -0.63 & 0.72 & $<0.001$ \\
\hline \multirow{4}{*}{ 3rd Week } & $\mathbf{R L}$ & 6.93 & 3.34 & 9.27 & 0.91 & $<0.001$ \\
\hline & RA & 17.17 & 2.25 & 18.87 & 1.93 & 0.003 \\
\hline & PT/DA & 0.87 & 4.30 & -1.60 & 4.05 & 0.026 \\
\hline & UV & 1.57 & 0.94 & -0.17 & 0.99 & $<0.001$ \\
\hline \multirow{11}{*}{ 6th Week } & RL & 6.43 & 1.77 & 8.97 & 1.03 & $<0.001$ \\
\hline & RA & 15.10 & 3.04 & 18.17 & 1.78 & $<0.001$ \\
\hline & PT/DA & 3.33 & 5.86 & -0.77 & 4.07 & 0.003 \\
\hline & uv & 2.13 & 1.36 & -0.13 & 1.17 & $<0.001$ \\
\hline & WDF & 15.33 & 6.58 & 25.17 & 5.80 & $<0.001$ \\
\hline & WPF & 18.63 & 6.05 & 25.33 & 7.30 & $<0.001$ \\
\hline & WRD & 5.33 & 2.41 & 5.97 & 2.33 & 0.305 \\
\hline & WUD & 10.83 & 2.70 & 18.67 & 5.07 & $<0.001$ \\
\hline & SUPINATION & 25.83 & 7.78 & 53.67 & 16.29 & $<0.001$ \\
\hline & PRONATION & 28.17 & 8.25 & 61.83 & 13.76 & $<0.001$ \\
\hline & GRIP STRENGTH & 26.67 & 6.61 & 26.00 & 8.85 & 0.742 \\
\hline \multirow{11}{*}{ 9th Week } & RL & 6.03 & 1.77 & 8.97 & 1.03 & $<0.001$ \\
\hline & RA & 14.47 & 3.26 & 18.20 & 1.77 & $<0.001$ \\
\hline & PT/DA & 4.13 & 6.64 & -0.83 & 4.07 & 0.001 \\
\hline & UV & 2.23 & 1.43 & -0.17 & 1.18 & $<0.001$ \\
\hline & WDF & 27.57 & 7.40 & 39.07 & 6.24 & $<0.001$ \\
\hline & WPF & 30.13 & 7.51 & 38.33 & 7.22 & $<0.001$ \\
\hline & WRD & 8.83 & 1.51 & 11.63 & 1.92 & $<0.001$ \\
\hline & WUD & 22.43 & 5.93 & 32.80 & 8.16 & $<0.001$ \\
\hline & SUPINATION & 43.50 & 12.74 & 81.33 & 8.28 & $<0.001$ \\
\hline & PRONATION & 48.27 & 12.38 & 84.57 & 5.08 & $<0.001$ \\
\hline & GRIP STRENGTH & 47.17 & 11.12 & 63.00 & 10.88 & $<0.001$ \\
\hline \multirow{11}{*}{ 3rd Month } & RL & 6.03 & 1.77 & 8.93 & 1.08 & $<0.001$ \\
\hline & RA & 14.40 & 3.33 & 18.20 & 1.77 & $<0.001$ \\
\hline & PT/DA & 4.10 & 6.77 & -0.83 & 3.97 & 0.001 \\
\hline & UV & 2.20 & 1.49 & -0.13 & 1.17 & $<0.001$ \\
\hline & WDF & 35.23 & 7.20 & 49.50 & 6.64 & $<0.001$ \\
\hline & WPF & 37.73 & 7.29 & 46.67 & 5.03 & $<0.001$ \\
\hline & WRD & 11.07 & 2.13 & 13.83 & 2.04 & $<0.001$ \\
\hline & WUD & 31.20 & 6.68 & 43.87 & 6.50 & $<0.001$ \\
\hline & SUPINATION & 60.57 & 11.38 & 88.93 & 2.24 & $<0.001$ \\
\hline & PRONATION & 66.27 & 10.59 & 89.87 & 0.51 & $<0.001$ \\
\hline & GRIP STRENGTH & 64.67 & 12.24 & 83.00 & 8.77 & $<0.001$ \\
\hline \multirow{11}{*}{ 6th Month } & RL & 5.73 & 2.00 & 8.93 & 1.08 & $<0.001$ \\
\hline & RA & 14.40 & 3.33 & 18.20 & 1.77 & $<0.001$ \\
\hline & PT/DA & 4.10 & 6.77 & -0.90 & 3.93 & 0.001 \\
\hline & UV & 2.20 & 1.49 & -0.17 & 1.18 & $<0.001$ \\
\hline & WDF & 39.87 & 7.21 & 53.20 & 6.32 & $<0.001$ \\
\hline & WPF & 42.73 & 6.28 & 49.20 & 2.58 & $<0.001$ \\
\hline & WRD & 11.87 & 2.56 & 14.47 & 1.61 & $<0.001$ \\
\hline & WUD & 37.00 & 6.63 & 47.13 & 3.99 & $<0.001$ \\
\hline & SUPINATION & 70.80 & 9.79 & 89.87 & 0.51 & $<0.001$ \\
\hline & PRONATION & 75.77 & 8.46 & 90.00 & 0.00 & $<0.001$ \\
\hline & GRIP STRENGTH & 78.67 & 9.00 & 90.67 & 6.40 & $<0.001$ \\
\hline
\end{tabular}

(RL-Radial length, RA-Radial inclination Angle, PT/DAPalmer Tilt/ Dorsal Angulation, UV-Ulnar Variance, WDFWrist Dorsiflexion, WPF-Wrist Palmerflexion, WRD-Wrist Radial Deviation, WUD-Wrist Ulnar Deviation: $\mathrm{p}<0.05$ ) Statistically significant difference was observed between both the groups regarding all the radiological parameters in each follow ups. Pin group had better radiological result than Cast group, except RA and PT/DA during first week where there was similar result. Regarding functional parameter we observed statistically significant difference between both group except WRD and grip strength at 6 weeks which was statistically not significant (Table 1; Case 1: fig 2 to5; Case 2: fig 6 to 9). Pin group had better patient satisfaction score than cast group ( $\mathrm{p}$ 0.012). There was no difference between cast and pin group regarding duration of fracture healing and cast/pin removal.

\section{Complications}

There was statistically significant difference in complications faced between both the groups $(\mathrm{p}<0.001)$ where complications were higher in cast group than pin group. (Fig 1)

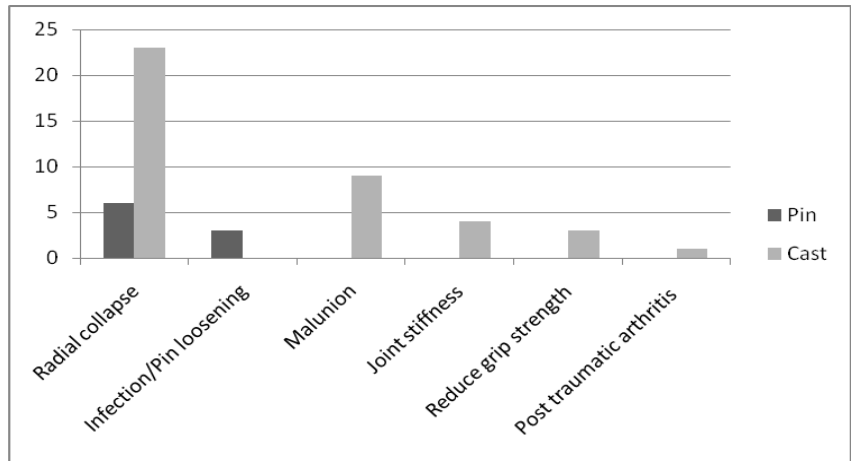

Fig 1. Bar diagram for Complications (cast vs. pin)

\section{DISCUSSION}

\section{Demographic profile}

The mean age group of cast group and pin group was 42.83 years and 27.63 years respectively. The mean age of all cases in our study was 35.23 years which was different from Mardani et $\mathrm{al}^{20} .(50.8 \pm 15)$, M. Akhter et al. 3 (45.45 \pm 14.13$)$, Harish et $\mathrm{al}^{21}$. (52.8 years) and Lenoble et $\mathrm{al}^{22}$. (57.7 years \pm 18.7). The difference in mean age in our study could be due to small sample size. The difference in mean age group between two treatment groups is by chance because of randomization. There were 32 male and 28 female patients ( $p$ 0.121) which was similar to Akhter et al. 3and Mardani et al. $(p=0.804) 20$ but different than Harish et al. ${ }^{21}$ and Wim et $\mathrm{al}^{23}$. where male to female ratio was $2: 1$. Fall on ground was the common mode of injury in both groups whereas RTA was the second common mode of injury which is similar to Akhter et al.3 Twenty eight patients had fracture of left wrist and 32 patients had fracture of right wrist which is similar to Akhter et al.3 There was also no difference in dominance of hand in both groups which was similar to Akhter et al.3 
2. Subjective satisfaction and radiological/functional outcome assessment

\section{a. Subjective Satisfaction Assessment}

We observed statistically significant difference in Satio grading (p 0.002) between two groups. $96.6 \%$ in pin group achieved excellent to good result whereas only $76.7 \%$ in cast group achieved these result which is comparable to Mardani et al. ${ }^{20}$, Abhishek et al. ${ }^{24}$, Akhter et al. ${ }^{3}$, Low et al. ${ }^{25}$, Rodriguez et al. $^{26}$, Baig et al. ${ }^{27}$ and Saeed et al. ${ }^{28}$

\section{b. Radiological Outcome Assessment}

All the radiological outcome parameters are comparable to the studies performed by Egol et al., ${ }^{29} \mathrm{M}$ Akhter et al., ${ }^{3}$ Rosenthal et al. ${ }^{16}$, Benoit et al. ${ }^{30}$, Fuji et al. ${ }^{19}$ and Lafontaine et al. ${ }^{31}$ except PT/DA which had inferior results in our study. But our PT/DA results are comparable to Fuji et al. ${ }^{19}$ where he observed palmer tilt angle to be 2.7 degree in 22 patients. Egol et al. ${ }^{29}$ found surgical intervention was able to maintain accepted fracture reduction parameters to a much greater extent than cast immobilization, and radiographic outcomes were superior with surgical intervention. At each follow-up interval, radial inclination angle and radial length were better in the operatively treated group, and at one year.

We usually did not want to overcorrect the dorsal tilt aiming Palmer angle to lie between 0-10 degree palmer tilt. We believe that up to 15 degree of dorsal tilt is acceptable and has less impact in the functional outcome until the patient is in highly functioning group. This thinking could have created differences in our PT/DA result from others.

c. Functional Outcome Assessment

In Egol et al. ${ }^{29}$ study, at six months, patients treated nonoperatively had better wrist extension only (59 degree compared with 50 degree; $p=0.04$ ), unlike our study where pin group had better wrist extension than Cast group (49.5 degree compared to 35.23 degree; $p<0.001$ ). Unlike his study, pin group in our study had better wrist flexion, radial and ulnar deviation than cast group. Similar to his study, Pin group in our study had better grip strength than cast group similar to Azzopardi et al. ${ }^{32}$, Rodriguez et al. ${ }^{26}$ and Shankar et al. ${ }^{33}$. In his study he noted modestly better supination in cast group than pin group unlike our study where pin group had better supination. Overall wrist movement was significantly better in the pin group than cast group similar to Gupta et al. ${ }^{34}$, Rodriguez et al. ${ }^{26}$ and Shankar et al. ${ }^{33}$

\section{Complications}

Overall complication rate was higher in cast group than pin group. Radial collapse $(p<0.001)$ and malunion $(p$ 0.004) were the common complications in cast group but all these parameter were within the acceptable range and imparted no significant deformity avoiding the need for remanipulation. Similar results were seen in studies performed by Rodriguez et al. ${ }^{26}$, Shankar et al. ${ }^{33}$, Verhulst et al. ${ }^{35}$ and Gupta et $\mathrm{al}^{34}$.

\section{CONCLUSION}

In conclusion, closed reduction and pinning had better radiological and functional outcomes compared to closed reduction and cast in the treatment of non comminuted extraarticular and partially articular distal radius fracture. Moreover, closed reduction and percutaneous pinning is a simple and safe procedure.

It is possible that with the large sample size and long term follow-up, the functional and radiological outcome would have more results than the present study. Therefore more studies need to be done with large sample size and for longer duration to get a clearer picture.

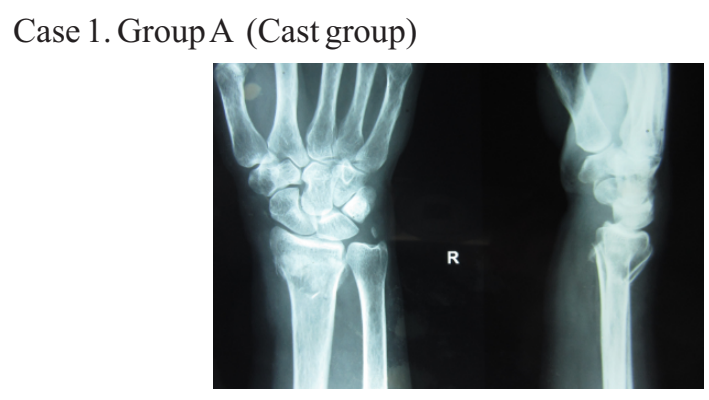

Fig 2. Sixty years female with distal radius fracture (Prereduction X-ray)

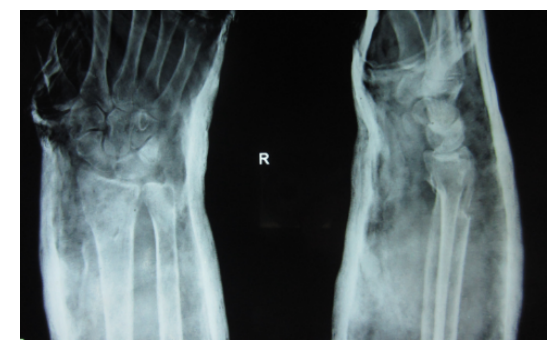

Fig.3 Sixty years female with distal radius fracture (Postreduction $\mathrm{X}$-ray after cast application)
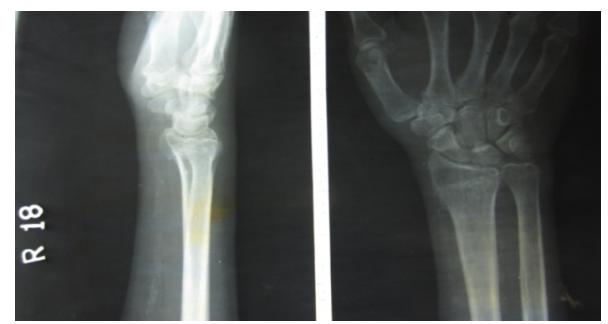
Fig.4 Sixty years female with distal radius fracture (Six months X-ray)

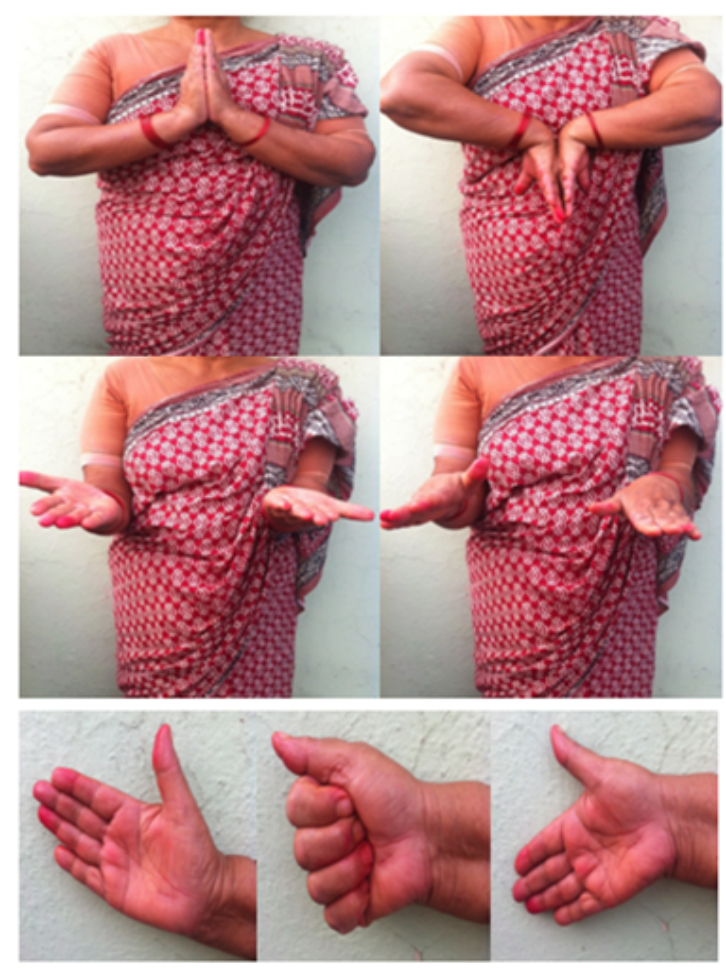

Fig.5 Sixty years female with distal radius fracture (Six months functional assessment)

Case 2 Group B (Pin group)

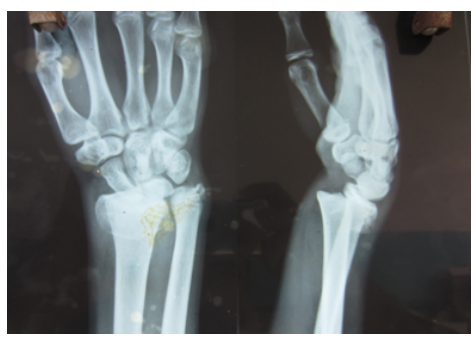

Fig.6 Thirteen years female with distal radius fracture (Preoperative X-ray)

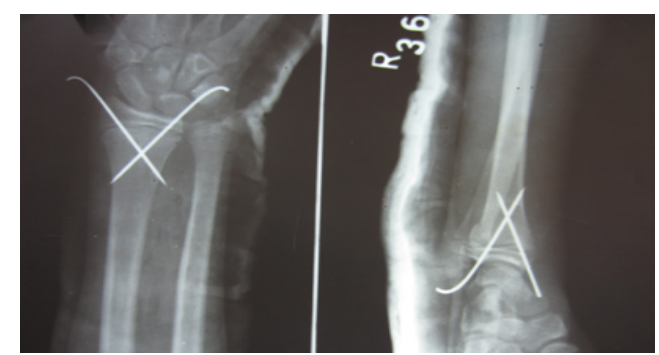

operative X-ray after CRPP)

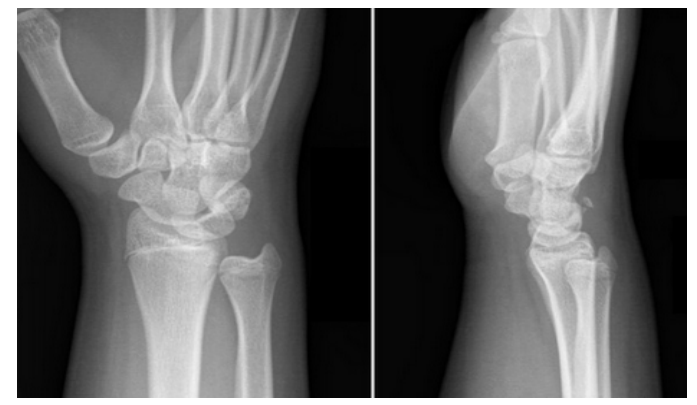

Fig.8 Thirteen years female with distal radius fracture (Six months X-ray)

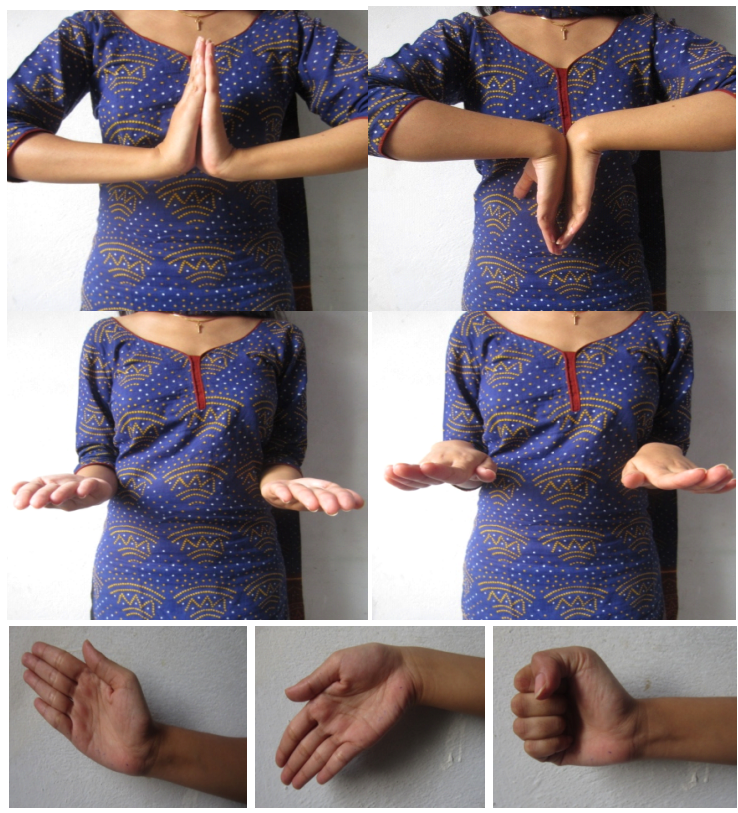

Fig.9 Thirteen years female with distal radius fracture (6 months functional assessment)

\section{REFERENCES}

1. Bucholz RW, Heckman JD, Brown CM: Distal radius and ulna fractures. Rockwood and Green's Fractures in Adults Philadelphia: Lippincot Williams and Wilkins; 5th ed. 2006;1:910.

2. Wigderowitz CA, Rowley DI, Mole PA, Peterson CR, Abel EW: $B o n e$ mineral density of radius in patients with Colles fracture $J$ Bone Joint Surg Br 2000;82(6):930-31.

3. M. Akhter, Baig Kashif Ahmed, S. Mujahid Humail: Closed Reduction And Percutaneous Kirschner Wire Fixation Of Displaced Colles Fracture In Adults. Pakistan journal of surgery 2008;24:31-7.

Fig.7 Thirteen years female with distal radius fracture (Post- 
4. Liporace FA, Adams MR, Capo JT, et al: Distal Radius Fractures. JOrthop Trauma 2009;23:739-48.

5. O'Neill TW, Cooper C, Finn JD, et al: Incidence of distal forearm fracture in British men and women. Osteoporosis Int $2001 ; 12: 555-8$

6. Mensforth RP, Latimer BM: Hamann-Todd collection aging studies: osteoporosis fracture syndrome. AmJ Phys Anthropol 1989;80(4):461-79.

7. Lester GE, Anderson JJ, Tylavsky FA, et al: Update on the use of distal radial bone density measurements in prediction of hip and colles'fracture risk. J Orthop Res 1990;8(2):220-6.

8. Slagel BE, Luenam S, Pichora DR: Management of post traumatic malunion of fractures of distal radius. OrthopClin North Am 2007;38:203-16.

9. Arora J, Kapoor H, Malik A, Bansal M: Closed reduction and plaster cast immobilization Vs external fixation in communited intra-articular fractures of distal radius. Indian $J$ Orthop 2004;38:113-7.

10. Gofton W, Liew A: Distal radius fractures: Nonoperative and percutaneous pinning treatment options. OrthopClin North Am 2007; 38:175-85.

11. Merchan ECR, Breton AF, Galindo E, Painado JF, Beltran J: Plaster cast versus Clyburn external fixation for fractures of the distal radius in patients under 45 years of age. OrthopRev 1992;21:1203-9.

12. Cooney WP, Dohyns JH, Linscheid RL: Complications of Colles fractures. JBone Joint Surg 1980;62A:613-19.

13. Miller BS, Taylor B, Widmann RF, et al: Cast Immobilization Versus Percutaneous Pin Fixation of Displaced Distal Radius Fractures in Children. JPediatr Orthop 2005;25:490-4.

14. Castaing $J$ : Recent fractures of the inferior extremity of the radius in the adult. Rev ChirOrthop French 1964;50:582-696.

15. RayhackJ: The history and evolution of percutaneous pinning of displaced distal radius fractures. OrthopClin North Am 1993;24:287-300

16. Rosenthal AH, Chung KC: Intrafocal pinning of distal radius fracture. Ann Plastic Surg 2002;48:593-9.

17. Putaman MD, Seitz WH: Fractures of the distal radius. Rockwood and Greens Fracture in Adults, Philadelphia: Lippincott, Williams \& Willkins; 5th ed. 2001;1:840-43.

18. E. K. Shin J. B. Jupiter: Current Concepts in the Management of Distal Radius Fractures.Acta chirurgiae orthopaedicae et traumatologiae? echosl 2007; 74:233-46.

19. Fuji K, Henmi T, Kanematsu Y, et al: Fractures of the distal end of radius in elderly patients: A Comparative study of anatomical and functional study. Journal of Ortho-paedic Surgery 2002;10(1):9-15.

20. Mardani Kivi M, Asadi K, Hashemi Motlagh K, Shakiba M: Distal Radius Fracture, a Comparison Between Closed Reduction and Long Arm Cast Vs. Closed Reduction and Percutaneous Pinning and Short Arm Cas. Shiraz E Medical Journal 2011 July;12(3).
21. Harish V, Kurup Vipul Mandalia, Anthony Shaju, Adrian Beaumont: Bicortical $K$-wires for distal radius fracture fixation : How many? Acta Orthop Belg 2007;73:26-30.

22. Lenoble E, Dumontier C, Goutallier D, Apoil A: Fracture of the distal radius: A prospective comparision between trans-styloid and Kapandji fixations.J Bone Joint Surg (Br) 1995;77-B:562-7.

23. Wim Van, Leemput Koen, De Ridder: Distal metaphyseal radius fractures in children : reduction with or without pinning. Acto Orthop Belg. 2009;75:306-9.

24. Abhishek K Das, Nandkumar Sundaram, Thiruvengita $G$ Prasad, Suresh K Thanhavelu: Percutaneous pinning for noncomminuted extra-articular fractures of distal radius. Indian $J$ Orthop 2011;45(5):422-6.

25. Low CK, Liau KH, Chew WY: Results of distal radial fractures treated by intrafocal pin fixation.Ann Acad Med2001;30:57376.

26. Rodriguez Merchan: Plaster cast versus Percutaneous pin fixation for comminuted fractures of the distal radius in patients between 46 and 65 years of age. J Orthop Trauma 1997;11(3):212-7.

27. Baig MA: Colles fracture fixation by percutaneous $K$-wire The Professional 2005 Mar;12(1):99-104.

28. Saeed KM, Ghouri SK, Ahmad I: Outcome of comminuted distal radial fracture treated by $N$. A. fixator. J Pak Orthop Assoc 2004;16(2):108-15

29. K.A. Egol, M. Walsh, S. Romo-Cardoso, Seth Dorsky, N Paksima: Distal Radial Fractures in the Elderly: Operative Compared with Nonoperative Treatment. J Bone Joint Surg Am 2010;92:1851-7.

30. Benoit LA, Freeland AE: Buttress pinning in the unstable distal radius fracture. A modification of Kapandji technique J Hand Surg Br 1995;20:82.

31. Lafontaine M, Hardy D, Delince P: Stability assessment of distal radius fractures. Injury 1989;20:208-10.

32. Azzopardi T, Ehrendorfer S, Coulton T, Abela M: Unstable extraarticular fractures of the distal radius: A prospective, randomised study of immobilisation in a cast versus supplementary percutaneous pinning. Journal of Bone and Joint Surgery - Br 2005;87(6):837-40.

33. Shankar NS, Craxford AD: Comminuted Colles' fractures: a prospective trial of management. Journal of the Royal College of Surgeons of Edinburgh 1992;37(3): 199-202.

34. Gupta R, Raheja A, Modi U: Colles fracture management by percutaneous crossed pin fixation versus plaster of Paris cast immobilization. Orthopedics 1999;22:680-82.

35. Verhulst D, Pimontel P, Puylaert D, Gijs T, Bogehams J: Single Kirschner wire fixation of Colles' fractures Orthopaedic Transactions 1990;14(3):654. 